\title{
Mikrostruktura kompozytowych powłok Ni-ZrC napawanych plazmowo
}

\author{
The microstructure of $\mathrm{Ni}$-ZrC composite coatings \\ deposited by plasma method
}

\section{Streszczenie}

W artykule przedstawiono wyniki badań kompozytowych napoin o osnowie stopu Ni umacnianych cząstkami ZrC. Warstwy te uzyskano poprzez napawanie plazmowe mieszaniny proszków - osnowy i fazy umacniającej na podłoża ze stali S355J0. Wykonano napoiny dla zmiennych wartości natężenia prądu łuku głównego. Przeprowadzono badania makro i mikroskopowe powłok kompozytowych stosując mikroskopię optyczną i skaningową. Określono objętościowy udział cząstek fazy umacniającej osnowę oraz stopień rozcieńczania napoiny metalem podłoża. Analizowano rozkład mikrotwardości osnowy. Wykazano, iż zachodzi dezintegracja cząstek proszku ZrC w skutek oddziaływania z ciekłą osnową metaliczną.

Słowa kluczowe: napoiny kompozytowe, $\mathrm{Ni}-\mathrm{ZrC}$, Napawanie plazmowe proszkowe, mikrostruktura

\begin{abstract}
The results of investigations of nickel base composite coatings reinforced by ZrC particles are presented in the paper. The layers were obtained by deposition of Ni-alloy and ZrC powders' mixture onto S355J0 low alloy steel by Plasma Powder Transferred Arc Welding method. Variable values of main welding current were applied. Macroscopic and microscope examinations of composite coatings were evaluated using optical and scanning microscopes. Volume fraction of reinforcing phase and dilution coefficient were evaluated. Microhardness of the matrix of composite coatings was also analyzed. It was evidenced that disintegration of $\mathrm{ZrC}$ particles occurred due to the action with liquid metal base.
\end{abstract}

Keywords: composite coatings, $\mathrm{Ni}-\mathrm{ZrC}$, Plasma Powder Transferred Arc Welding, microstructure

\section{Wstęp}

Napawanie plazmowe proszkowe (ang. PPTAW) należy do ważnych spawalniczych metod stosowanych w modyfikacji i regeneracji powierzchni części maszyn. Zalety tej metody oraz zastosowanie napawania plazmowego zostało szeroko omówione $w$ literaturze $[1,2]$. Jedną z cennych zalet tej metody jest możliwość otrzymywania napoin o zróżnicowanym składzie chemicznym, w tym warstw kompozytowych. Napoiny kompozytowe o strukturze metalicznej umacniane są cząstkami twardych faz, na ogół węglikami, azotkami, borkami. Tego typu powłoki łączą w sobie cechy odpornej na zużycie a jednocześnie plastycznej osnowy oraz twardej ceramiki i wychodzą na przeciw potrzebom przemysłowym wszędzie tam, gdzie występuje duże obciążenie ścierne.

Materiał osnowy napoin kompozytowych stanowią prze-

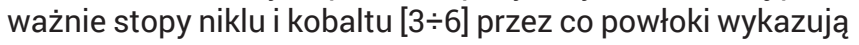
odporność na korozję i zachowują wysokie właściwości mechaniczne w podwyższonej temperaturze oraz tańsze stopy żelaza stosowane do nakładania warstw na mniej odpowiedzialne części maszyn [7]. Wzrost właściwości mechanicznych uzyskuje się poprzez dodatek wysokotopliwych faz, często węglików metali przejściowych z IVB - VIB grupy układu okresowego pierwiastków. Węgliki te charakteryzują się przede wszystkim dużą twardością, odpornością na zużycie ścierne i korozyjne oraz wysoką stabilnością termodynamiczną $[8,9]$ i ich dodatek znacznie poprawia właściwości eksploatacyjne napoin.

Stosunkowo dużo prac poświęcono otrzymywaniu i badaniu powłok kompozytowych z dodatkiem węglików chro-

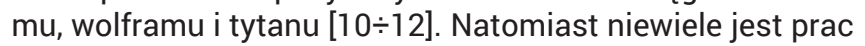
poświęconych badaniom napoin kompozytowych otrzymanych metodą plazmową umacnianych węglikami przejściowymi, takim jak: ZrC, HfC, MoC, NbC, TaC [13]. Węgliki te również posiadają bardzo wysokie właściwości a napoiny z ich dodatkiem wykazują atrakcyjne cechy użytkowe [14].

W artykule przedstawiono wyniki badań kompozytowych powłok Ni-ZrC otrzymywanych metodą plazmową z mieszaniny proszków dla różnych parametrów napawania. Szczególną uwagę poświęcono badaniom strukturalnym napoin $\mathrm{Ni}$-ZrC. Podjęta tematyka stanowiącym kontynuację wcześniejszego cyklu badań $[15,16]$.

\section{Przygotowanie próbek, materiały i urządzenia}

Kompozytowe powłoki Ni-ZrC napawano na podłoża ze stali niskostopowej S355J0. Do napawania przygotowano próbki o wymiarach $150 \times 50 \times 10 \mathrm{~mm}$. Przed procesem napawania powierzchnię próbek dokładnie oczyszczono i odtłuszczono.

Do napawania stosowano mieszaninę proszków, w której osnowę stanowił proszek na bazie niklu o symbolu DA 22. Oprócz niklu proszek ten zawiera: 0,03\% C, 2,4\% Si, 1,4\% B 
oraz $0,4 \%$ Fe. Proszek osnowy mieszano z proszkiem węglika cyrkonu w proporcji 60:40 (objętościowo). Ziarnistość obu proszków była taka sama i mieściła się w przedziale od 50 do $150 \mu \mathrm{m}$.

Próby napawania przeprowadzono stosując urządzenie PTA 301 Control M firmy Hettiger. Przed wykonaniem właściwych napoin wykonano wstępne próby napawania mające na celu dobór parametrów procesu. $\mathrm{Na}$ ich podstawie ustalono stałe i zmienne parametry napawania. Napoiny kompozytowe wykonano dla zmiennych wartości prądu łuku głównego mieszczących się w zakresie 60-120 A. Pozostałe parametry w trakcie procesu napawania były stałe i ważniejsze $\mathrm{z}$ nich przedstawiono $\mathrm{w}$ tablicy $\mathrm{I}$.

Tablica I. Parametry napawania

Table I. Surfacing parameters

\begin{tabular}{|c|c|}
\hline Parametr & Wartość \\
\hline Natężenie prądu łuku wewnętrznego & $40 \mathrm{~A}$ \\
\hline Napięcie łuku plazmowego & $25 \mathrm{~V}$ \\
\hline Wydatek proszku & $6 \mathrm{~g} / \mathrm{min}$ \\
\hline Szybkość napawania & $50 \mathrm{~mm} / \mathrm{min}$ \\
\hline $\begin{array}{c}\text { Wydatek gazu (argon): } \\
\text { plazmotwórczego } \\
\cdot \text { osłonowego }\end{array}$ & $\begin{array}{c}1,5 \mathrm{l} / \mathrm{min} \\
8 \mathrm{I} / \mathrm{min} \\
5 \mathrm{I} / \mathrm{min}\end{array}$ \\
\hline transportującego & $8 \mathrm{~mm}$ \\
\hline Amplituda oscylacji & $450 \mathrm{~mm} / \mathrm{min}$ \\
\hline Szybkość ruchu oscylacyjnego & $15 \mathrm{~mm}$ \\
\hline $\begin{array}{c}\text { Odległość plazmotronu od przedmiotu } \\
\text { napawanego }\end{array}$ & $4 \mathrm{~mm}$ \\
\hline Średnica dyszy zwężającej &
\end{tabular}

\section{Wyniki badań}

Po procesie napawania kompozytowe powłoki poddano obserwacjom makroskopowym. Badania prowadzono okiem nieuzbrojonym. Na ich podstawie stwierdzono, że wszystkie napoiny posiadają poprawny wygląd.

Następnie przygotowano próbki do badań mikroskopowych. Z każdej napoiny wycinano fragment do badań. Z uwagi na wysoką twardość napoin cięcie prowadzono na wycinarce elektroerozyjnej. Próbki wycinano w tej samej odległości od początku ściegu w celu zapewnienia poprawności wnioskowania. Zgłady metalograficzne przygotowano wg standardowej procedury.

Do obserwacji i rejestracji mikrostruktury wykorzystano stanowisko wyposażone w mikroskop metalograficzny Olympus IX70 z cyfrowym zapisem obrazu. Badania mikroskopowe ujawniły niezgodności spawalnicze w powłokach kompozytowych wykonanych przy natężeniu prądu 60 i 70A. W warstwach tych na granicy międzyfazowej powłokapodłoże występowały przyklejenia (rys. 1a). Ponadto widoczne były duże pęcherze gazowe w napoinie na granicy międzyfazowej osnowa-węglik zlokalizowane na ogół w okolicy linii wtopienia (rys. 1b). W powłokach napawanych z większą energią liniową nie obserwowano wyżej wymienionych niezgodności spawalniczych. Na rysunku 2 przedstawiono przykład struktury napoiny kompozytowej Ni-ZrC wykonanej przy natężeniu prądu 80A. Na tle jasnej osnowy rozmieszczone są ciemne cząstki węglika cyrkonu. Granica międzyfazowa napoina kompozytowa - stalowe podłoże jest ciągła pozbawiona niezgodności spawalniczych, co świadczyć może o dobrej przyczepności tych powłok do materiału podłoża.
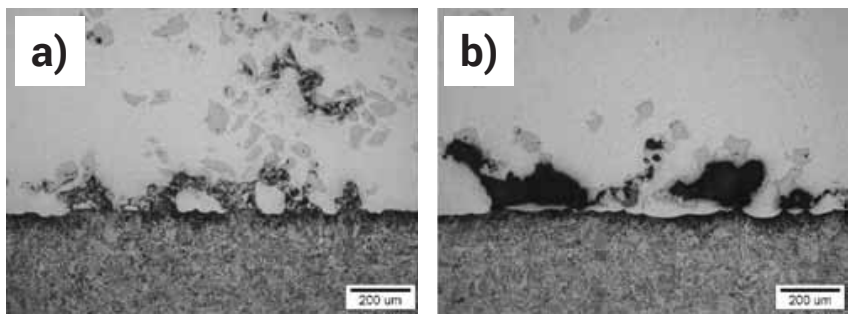

Rys. 1. Niezgodności spawalnicze w napoinach kompozytowych Ni-ZrC wykonane przy zbyt niskim natężeniu prądu: a) przyklejenia napoiny do materiału podłoża $(I=60 \mathrm{~A})$, b) pęcherze gazowe zlokalizowane przy linii wtopienia $(I=70 \mathrm{~A})$

Fig. 1. The welding discrepancies in $\mathrm{Ni}-\mathrm{ZrC}$ composite coatings obtained with too low welding current: a) interrun fusion defect $(I=60 A), b)$ gas pocket located at fusion line $(I=70 A)$

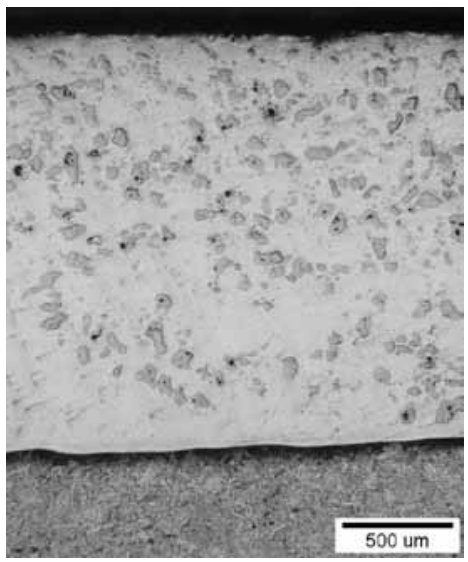

Rys. 2. Przekrój poprzeczny napoiny Ni-ZrC uzyskanej przy prądzie napawania $80 \mathrm{~A}$ Fig. 2. The cross-section of $\mathrm{Ni}$-ZrC layer obtained with surfacing current of $80 \mathrm{~A}$

Na rysunku 3 przedstawiono morfologię fazy umacniającej kompozytowych powłok. Widoczne są duże nieregularne cząstki ZrC oraz mniejsze rozmieszczone wokół dużych aglomeratów. Udział małej frakcji ZrC spowodowany jest prawdopodobnie rozpadem większych ziaren umocnienia pod wpływem oddziaływania łuku plazmowego bądź na skutek reakcji z ciekłą osnową Ni. Na rysunku 4 przedstawiono dezintegrację dużych aglomeratów ZrC. Widoczna jest penetracja ciekłej osnowy po granicach ziarn ZrC (rys. 4). Obecność drobnej frakcji ZrC w osnowie jest wynikiem oddzielania się i rozpadu warstwy przypowierzchniowej większych aglomeratów ZrC. Granica międzyfazowe węglik-osnowa jest ciągła (rys. 4). Obserwacje przy większych powiększeniach tej granicy nie wykazały obecności strefy przejściowej - rysunku 5. Świadczą o tym także mapy rozkładu pierwiastków stopowych (rys. 5). Z map tych wynika także brak obecności Zr w osnowie.

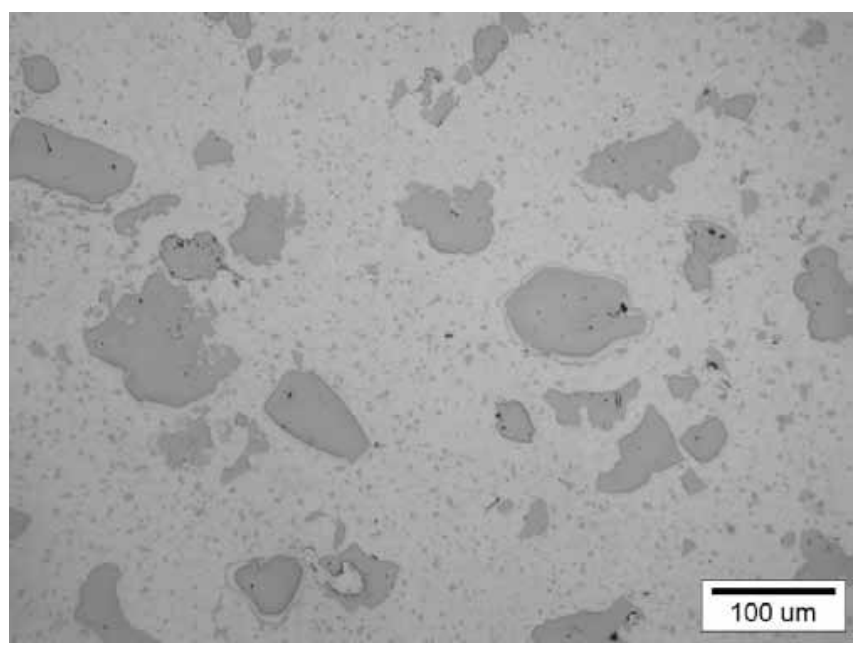

Rys. 3. Morfologia fazy umacniającej w kompozytowych powłokach $\mathrm{Ni}-\mathrm{ZrC}$

Fig. 3. Strengthening phase morphology in Ni-ZrC composite coatings 


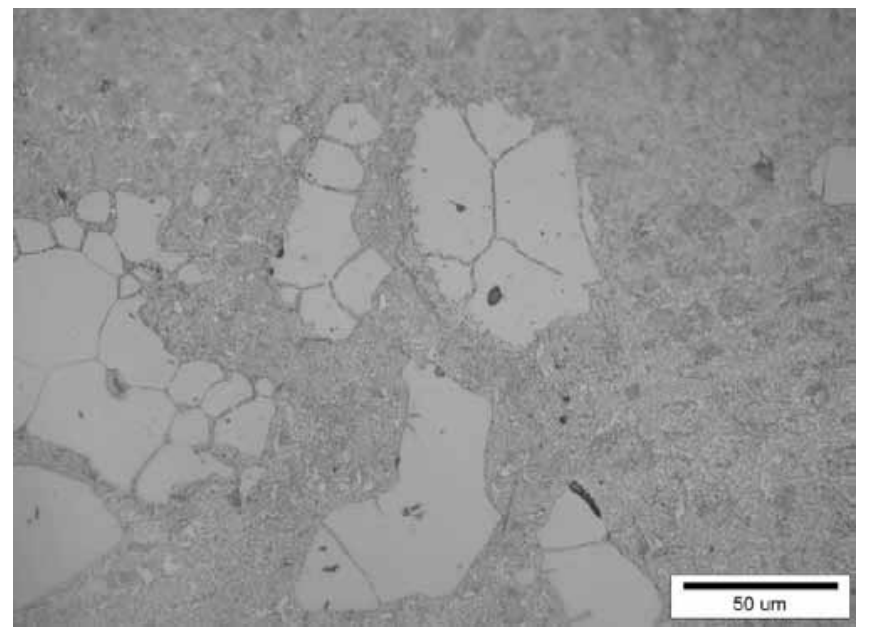

Rys. 4. Penetracja ciekłej osnowy po granicach ziaren dużych aglomeratów fazy umacniającej

Fig. 4. Penetration of liquid matrix into grain boundaries of large agglomerates of strengthening phase
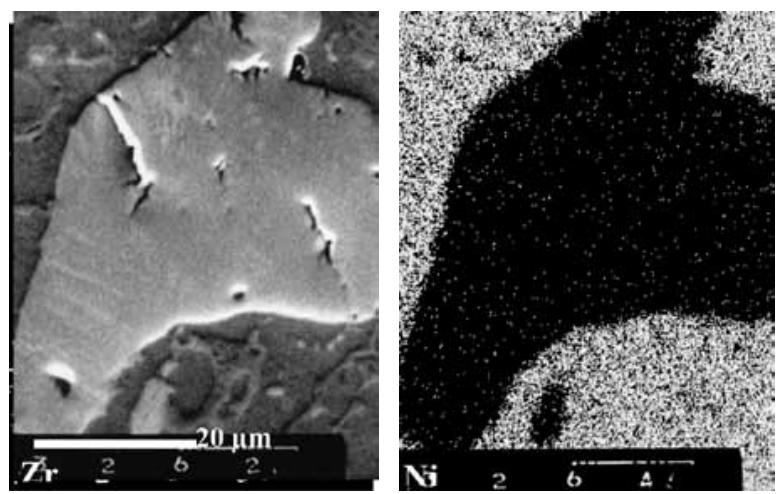

Rys. 5. Mikrostruktura granicy międzyfazowej węglik-osnowa oraz powierzchniowe rozkłady $\mathrm{Zr}$ i Ni

Fig. 5. The microstructure of the carbide-matrix interface and surface distribution of $\mathrm{Zr}$ and $\mathrm{Ni}$

Wykonano obliczenia udziału metalu podłoża (D) w napoinie wg wzoru (1), gdzie: P - powierzchnia przekroju nadtopionego metalu podłoża, $S$ - powierzchnia przekroju napawanego metalu. Otrzymane wyniki (rys. 6) wskazują, że wraz ze wzrostem natężenia prądu rośnie udział metalu podłoża w napoinie.

$$
D=\frac{P}{P+S} \times 1 \quad 0 \quad 0 \quad \%
$$

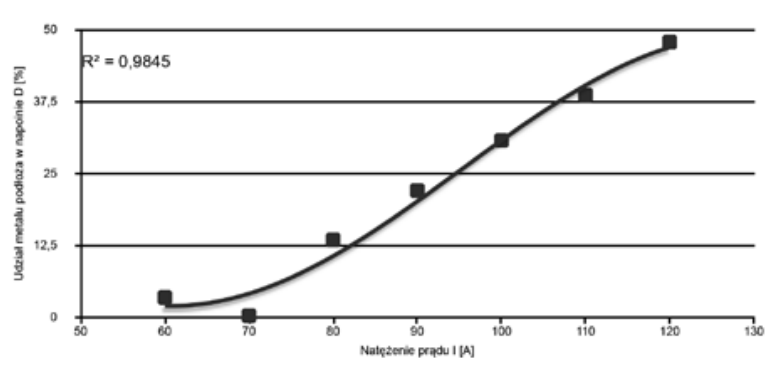

Rys. 6. Udział procentowy metalu podłoża w napoinie w funkcji natężenia prądu napawania

Fig. 6. Percentage of substrate material content in overlays as a function of main welding current

Za pomocą programu komputerowego MultiScanBase wykonano obliczenia udziału objętościowego fazy umacniającej osnowę. Badania prowadzono na przekrojach poprzecznych przy powiększeniu x100. Do badań przygotowano obrazy w formie binarnej a obliczenia prowadzono z całego pola przekroju napoiny. Otrzymane wyniki w funkcji natężenia prądu napawania przedstawiono na rysunku 7.
Przedstawione wyniki wskazują, że udział objętościowy ZrC rośnie wraz ze wzrostem natężenia prądu, lecz tylko do wartości ok. $90 \mathrm{~A}$. Dalszy wzrost natężenia prądu nie skutkuje zwiększeniem udziału fazy umacniającej.

Pomiar mikrotwardości osnowy napoin kompozytowych wykonano w osi napoiny prostopadle do linii wtopienia stosując obciążenie $100 \mathrm{~g}$. Mierzono twardość napoin wykonanych dla natężenia prądu 60, 90 i 120 A. Otrzymane wyniki przestawiono na rysunku 8.

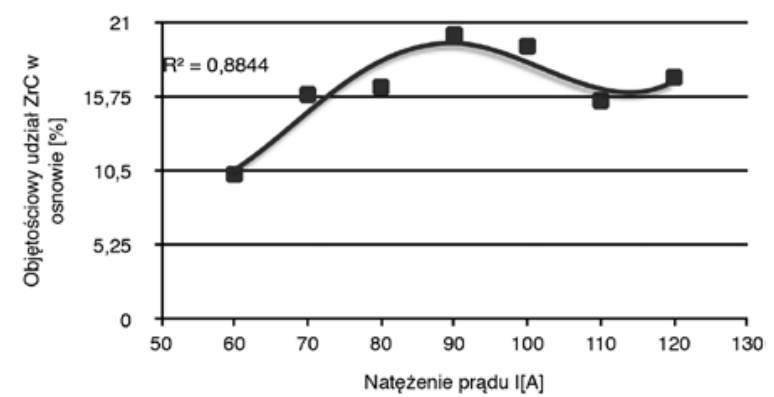

Rys. 7. Objętościowy udział ZrC w osnowie powłok kompozytowych w zależności od natężenia prądu napawania

Fig. 7. Volume fraction of $\mathrm{ZrC}$ in the matrix of composite coatings versus the main welding current applied

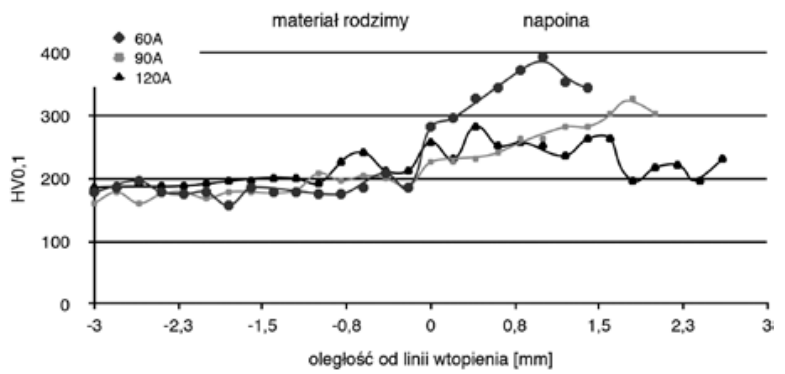

Rys. 8. Rozkład mikrotwardości osnowy prostopadle do granicy warstwa - podłoże

Fig. 8. Distribution of matrix microhardnes perpendicular to the layer - substrate boundary

\section{Omówienie wyników badań}

Z przeprowadzonych badań wynika, że warunkiem otrzymania poprawnych napoin kompozytowych Ni-ZrC jest stosowanie odpowiednio wysokiego natężenia prądu ( $\geq 80 \mathrm{~A})$. Przy zbyt niskiej energii liniowej procesu materiał podłoża nadtapiany jest tylko miejscowo w efekcie czego tworzą się przyklejenia napoiny do napawanego metalu (rys. 1a). Obecność dużych pęcherzy na granicy osnowa-węglik wynika ze słabszego zwilżania ZrC ciekłym stopem $\mathrm{Ni}$ (rys. 1b). Z danych literaturowych wynika, że ZrC charakteryzuje się metalicznym charakterem wiązania chemicznego z pewnym udziałem wiązań kowalencyjnych a nawet jonowych. To utrudnia zwilżanie węglika ciekłą osnową i negatywnie wpływa na proces formowania się napoin. Wzrost energii liniowej podnosi temperaturę ciekłego jeziorka i wydłuża czas kontaktu cząstek węglika z ciekłą osnową, co z kolei sprzyja lepszemu zwilżeniu cząstek fazy umacniającej. Dlatego poprawne napoiny uzyskano dla wyższych wartości energii liniowej - rysunek 2.

W kompozytowych powłokach Ni-ZrC węglik cyrkonu występował w postaci zarówno dużych jak i małych, nieregularnych cząstek. Obecność małej frakcji nie wynika z jej udziału w wyjściowej mieszaninie proszków lecz jest efektem rozpadu dużych aglomeratów ZrC w trakcie procesu napawania. Obserwowano dwa mechanizmy tworzenia się małych cząstek węglika. Pierwszy z nich to penetracja ciekłej osnowy po granicach dużych ziaren ZrC (rys. 4a). Drugi me- 
chanizm to dezintegracja warstwy powierzchniowej cząstek fazy umacniającej w efekcie której powstaje znaczna ilość małej frakcji węglika cyrkonu. Z powierzchni dużych cząstek węglika odseparowuje się wąski pasek ZrC, który następnie ulega rozpadowi na mniejsze części (rys. 4b).

Granica międzyfazowa węglik-osnowa jest ciągła bez widocznej strefy przejściowej pomiędzy fazami na tej granicy (rys. 5). Powyższe stwierdzenie dokumentują także wyniki rozkładu powierzchniowego pierwiastków Ni i Zr. Nie ujawniono obecności Zr w osnowie, co świadczy o braku rozpuszczalności w niej tego węglika.

Udział metalu podłoża w napoinie zwiększa się wraz ze wzrostem natężenia prądu ponieważ zwiększa się energia liniowa procesu. To z kolei prowadzi do większego nadtopienia materiału podłoża i w konsekwencji większego jego udziału w napoinie.

Objętościowy udział fazy umacniającej także zwiększa się wraz ze wzrostem natężenia prądu napawania ale tylko dowartościok.90A(rys.7). Możetoświadczyćo znaczącym udziale wiązania kowalencyjnego w ZrC, co utrudnia wprowadzenie tego węglika do ciekłej osnowy ale wzrost natężenia prądu, poprzez aktywację termiczną procesu zwilżania powoduje utrzymanie coraz większej ilości ZrC w ciekłym jeziorku. Wzrost natężenia prądu powyżej $90 \mathrm{~A}$ nie skutkuje zwiększeniem udziału fazy umacniającej, ponieważ ciekłe jeziorko powiększa się na skutek głębszego wtopienia w materiał podłoża. Maksymalne wartości udziału fazy umacniającej występujące przy natężeniu prądu 90-100 A wynoszą ok. $20 \%$ i są znacznie mniejsze niż zawartość węglika w wyjściowej mieszaninie proszków.

Rozkład mikrotwardości osnowy powłok kompozytowych zmniejsza się ze wzrostem natężenia prądu napawania ponieważ zwiększa się stopień rozcieńczenia napoiny metalem podłoża. Stosunkowo mała objętość fazy umacniającej wprowadzanej do ciekłej osnowy oraz brak rozpuszczalności ZrC nie równoważy spadku twardości osnowy wynikającego z większego udziału Fe z nadtopionego podłoża.

\section{Wnioski}

- Napoiny kompozytowe Ni-ZrC formują się poprawnie przy odpowiednio wysokim natężeniu prądu łuku głównego. Powłoki napawane przy niedostatecznie wysokiej energii liniowej nie wykazują metalurgicznego połączenia z podłożem oraz występują w nich duże pęcherze gazowe.

- W kompozytowych powłokach Ni-ZrC węgli cyrkonu występował w postaci dużych, nieregularnych cząstek oraz znacznie mniejszych niż w wyjściowej mieszaninie proszków. Udział mniejszej frakcji ZrC jest efektem dezintegracji dużych aglomeratów węglika na skutek reakcji z ciekłą osnową.

- Granica międzyfazowa węglik-osnowa jest ciągła bez widocznych stref przejściowych.

- Stopień rozcieńczenia napoiny metalem podłoża zwiększa się wraz ze wzrostem natężenia prądu.

- Udział objętościowy ZrC zwiększa się wraz ze wzrostem natężenia prądu do wartości 90A. Jest to efekt aktywacji cieplnej procesu zwilżania ZrC ciekłym stopem Ni. Dalszy wzrost natężenia prądu prowadzi do większego rozcieńczenia napoiny materiałem podłoża i w efekcie do spadku udziału objętościowego ZrC.

- Wzrost natężenia prądu napawania powoduje spadek twardości osnowy powłok kompozytowych w wyniku zwiększającego się udziału żelaza z nadtopionego podłoża.

Badania były finansowane z grantu NCBiR/KGHM nr CuBR/1/3NCBR/2014.

\section{Literatura}

[1] Klimpel A.: „Technologie napawania i natryskiwania cieplnego”, Wyd. P.Śl., Gliwice 1999

[2] Jitai N., Wei G., Mianhuan G., Shixiong L.: „Plasma application in thermal processing of materials", Vacuum 65, 2002, 263-266.

[3] Ozel S., Kurt B., Somunkiran I., Orhan N.: „Microstructural characteristic of NiTi coating on stainless steel by plasma transferred arc process", Surface \& Coatings Technology, 2008, No 202, 3633-3637.

[4] Aoh J. N., Jeng Y. R., Chu E. L., Wu L. T.: „On the wear behavior of surface clad layers under high temperature", Wear, 1999, No 225-229, 1114-1122.

[5] Kim H. J., Kim Y. J.: „Wear and corrosion resistance of PTA weld surfaced Ni and Co based alloy layers" Surface Engineering, 1999, Vol. 15, No 6, 495-501.

[6] Gurumoorthy K., Kamaraj M., Prasad Rao K., Sambasiva Rao A., Venugopal S.: „Microstructural aspects of plasma transferred arc surfaced Ni-based hardfacing alloy", Materials Science and Engineering A, 2007, No 456, 11-19.

[7] Kim H. J., Yoon B. H., Lee Ch. H.: „Wear performance of the Fe-based alloy coatings produced by plasma transferred arc weld-surfacing process", Wear, 2002, No 249, 846-852.

[8] Oyama S. T.: "The Chemistry of transition metal carbides and nitrides", Balckie Academic \& Professional, Chapman \& Hall, London, 1996.

[9] Stolarz S.: „Wysokotopliwe związki i fazy”, Wyd. Śląsk, Katowice 1974.
[10] Aoh J. N., Jeng Y. R., Chu E. L., Wu L. T.: „On the wear behavior of surface clad layers under high temperature”, Wear, 1999, No 225-229, 1114-1122.

[11] Kim H. J., Yoon B. H., Lee Ch. H.: „Sliding wear performance in molten $\mathrm{Zn}-\mathrm{Al}$ bath of cobalt-based overlayers produced by plasma-transferred arc weld-surfacing", Wear, 2003, No 254, 408-414.

[12] Huang Z., Hou Q., Wang P.: „Microstructure and properties of $\mathrm{Cr} 3 \mathrm{C} 2$ - modified nickel - based alloy coating deposited by plasma transferred arc process", Surface \& Coatings Technology, 2008, No. 202, $2993-2999$.

[13] Hung F. Y., Yan Z. Y., Chen L. H., Lui T. S.: „Microstructural characteristics of PTA-ocverlayed NbC on pure Ti”, Surface \& Coatings Technology, 2006, No. 200, 6881-6887.

[14] Corujeira-Gallo S., Alam N.: „Wear Assessment of Fe-TiC/ZrC Hardfacing Produced from Oxides", Tribology in Industry, 2015, Vol. 37, No. 1, 66-71.

[15] Bober M., Senkara J.: „Dystrybucja fazy umacniającej w napoinach kompozytowych Ni-WC". Prace Naukowe - Mechanika, z.215, 59-69s; wyd. Oficyna Wydawnicza Politechniki Warszawskiej, Warszawa 2006;

[16] Bober M., Senkara J.: „Napoiny na osnowie niklu z węglikami tytanu - otrzymywanie i struktura", Prace naukowe - Mechanika, z. 229, 65-74, wyd. Oficyna Wydawnicza Politechniki Warszawskiej, Warszawa 2009. 